\title{
Evolução da educação no Brasil: uma análise das taxas entre 1970 e 2000 segundo o grau da última série concluída
}

\author{
Moema Gonçalves Bueno Fígoli*
}

\begin{abstract}
Neste artigo analisam-se os diferenciais nas taxas do grau mais alto de educação alcançado, no Brasil, por pessoas de 15 anos e mais, entre 1970 e 2000, segundo grupos de idade e sexo. Para os grupos de idades mais elevadas, o crescimento na educação formal parece ter redundado em aumento na proporção de pessoas com pelo menos uma série concluída do ensino fundamental, enquanto para os mais jovens teve maior significado o crescimento na proporção daquelas com pelo menos um ano concluído de ensino médio e superior. A análise por coorte mostrou uma maior expansão, ao longo do período, da proporção de pessoas nos ensinos médio e superior, para as coortes mais jovens e as mulheres. A estrutura etária mais envelhecida, em 2000 , tem pouco efeito no crescimento da educação no país e atua no sentido de diminuir a diferença entre as taxas de prevalência de 1970 e 2000 para os graus: nenhuma educação formal, fundamental e médio. Já com relação ao nível superior, ela coopera com o aumento da diferença. A distribuição por educação dos imigrantes internacionais legais registrados pelos censos de 1991 e 2000 colabora para o aumento das taxas nos graus mais altos de educação.
\end{abstract}

Palavras-chave: Educação alcançada. Imigração e educação. Envelhecimento e educação.

\section{Introdução}

O comportamento das variáveis demográficas e econômicas tem sido freqüentemente estudado considerando-se os diferenciais na distribuição da população por educação. O nível de fecundidade, por exemplo, tem mostrado, constantemente, uma relação inversa com a educação da mãe. Também verifica-se que a mortalidade na infância é maior entre as crianças filhas de mães com menor escolaridade. ${ }^{1}$ Apesar de a mortalidade adulta entre os grupos com menos anos de estudo ser superior à daqueles que possuem mais instrução, conforme estudos realizados em países desenvolvidos, o diferencial tem, em geral, apresentado maior variação relativa entre os adultos mais jovens do que entre os mais velhos, assim como mais para os homens do que para as mulheres. ${ }^{2}$ Além disso, mostram alguns estudos que o nível de

\footnotetext{
*Professora do Departamento de Demografia da Universidade Federal de Minas Gerais e pesquisadora do Centro de Desenvolvimento e Planejamento Regional (Cedeplar) desta Universidade. Doutora em Demografia.

${ }^{1}$ Evidências deste fato no Brasil podem ser encontradas em Sawyer e Soares (1982); Fernandes (1984); Hakkert (1986); Castilla (1996); Santos e Moura (1998); Sastry (1996:2004).

2 Veja por exemplo: Kunst e Mackenbach (1994); Desplanques (1976;1984); Elo e Preston ( 1996); Pappas et al. (1993); Feldman et al. (1989); Shkolnikov et al. (1998).
} 
educação dos países pode ser afetado pela migração internacional, uma vez que a escolaridade dos migrantes e da população residente é, com freqüência, desigual. ${ }^{3}$

Por outro lado, como se sabe, os estudos econômicos têm enfatizado o importante papel da educação no crescimento econômico. ${ }^{4}$ Alain Mingat e Jee-Peng Tan (1996) concluíram que a variação da taxa de retorno decorre não somente do nível de educação, mas também desse em relação ao nível de desenvolvimento do país; portanto, a avaliação da taxa de retorno demanda considerar ambas variáveis simultaneamente. Segundo os autores, para os países com menor renda, o melhor seria investir em educação primária, enquanto para aqueles de renda média, onde a educação primária já é extensa, o investimento deveria ser em educação secundária e, para os de alta renda, o retorno seria maior se o investimento fosse feito em educação terciária.

A importância da desagregação da população por grau de educação, para projeções populacionais, é discutida por Lutz et al. (1999) e referida por Goujon e Lutz (2000, p.125):

adding education to age and sex as an explicit considered demographic dimension in population forecasting also affects the demographic output parameters themselves, because a significant source of so far unobserved heterogeneity is being observed and indigenized explicitly. It may, therefore, be considered an improvement, even of the purely demographic output parameters of the projection. More importantly, however, the overriding substantive importance of education means that the future educational composition of the population is of interest in its own right.

De fato, mesmo se as taxas específicas de mortalidade, fecundidade e migração da população em cada grau de educação se mantiverem constantes, a mudança do tamanho relativo da população em cada grau educacional, ao longo do tempo, resuItará em modificação na taxa da população total.

Muitos estudos têm usado as taxas de matrícula e de analfabetismo como medidas do nível de educação da população, mas, como salientado por Barro e Lee (1993 e 2000), estas variáveis não medem o estoque de capital humano disponível. A taxa de matrícula, por exemplo, reflete o fluxo corrente de capital humano, mas, como o processo educacional é lento, há um longo intervalo entre o fluxo e o estoque de educação. Além disso, a informação sobre matrícula normalmente refere-se ao número de estudantes no início do ano escolar, não se tendo, dessa forma, informação sobre a quantidade de estudantes que efetivamente cursaram a escola durante todo esse período. A taxa de analfabetismo, por sua vez, é uma medida muito agregada do estoque de capital humano, pois mede o estágio inicial de educação e não reflete a real qualificação da população.

Em razão das considerações precedentes, neste trabalho serão analisados os diferenciais nas taxas de educação do Brasil, segundo o grau mais alto alcançado, por pessoas de 15 anos e mais, entre 1970 e 2000, por grupos de idade e sexo, tanto do ponto de vista de período como de coorte, com o objetivo de avaliar o comportamento, ao longo do tempo, do estoque de educação final da população. Serão também discutidos os possíveis impactos da migração internacional e dos diferenciais de mortalidade, por educação, nas taxas de prevalência. ${ }^{5}$ Finalmente, será analisado o efeito da mudança da estrutura etária da população no período, sobre as taxas de educação total.

\section{Dados}

As análises deste trabalho baseiam-se nos microdados do resultado da amostra

\footnotetext{
${ }^{3}$ Consulte: Borjas( 1994 e 1999); Chiswisk (1986).

${ }^{4}$ Veja, por exemplo, Psacharopoulos e Patrinos (2002), que revisaram uma série de estudos em países em vários estágios de desenvolvimento.

${ }^{5}$ Número de pessoas do grupo de idade com pelo menos uma série concluída do grau, dividido pelo total de pessoas no grupo etário.
} 
dos censos de 1970, 1980, 1991 e 2000, fornecidos pelo IPUMS International (Integrated Public Use Microdata Series) Census Microdata for Social and Economic Research. Os dados do censo de 1991 foram ajustados para 1990, de forma a permitir a comparabilidade dos resultados em intervalos de dez anos. Nessa base de dados, os registros individuais de graus de educação alcançados, relativos ao Brasil, estão classificados nas seguintes categorias:

Menos que primário completo

Nenhum

Algum primário

Primário - quatro anos

Primário completo menos que secundário

Primário (6)

Menos que secundário

Secundário completo

Secundário somente

Alguma Universidade

Universidade completa

Os graus de educação alcançados, que foram considerados neste trabalho são:

- nenhum - abrange pessoas que não completaram nenhum grau de educação formal;

- fundamental - inclui todas as pessoas que completaram, com aprovação, pelo menos um ano de educação do primeiro ciclo formal e, no máximo, oito anos, mas que não passaram para o ciclo seguinte;

- médio ou secundário - inclui todos que têm mais de oito anos de estudos completados, com aprovação, mas não cursaram nenhuma série do grau terciário ou superior;

- terciário ou superior - engloba aqueles que cursaram pelo menos um ano de ensino superior, tendo ou não completado o curso.
Esta classificação baseia-se nos níveis e graus atualmente utilizados no sistema educacional brasileiro. No entanto, como várias modificações foram introduzidas na organização do mesmo, entre 1970 e 2000, ${ }^{6}$ e procurando tornar comparáveis os graus de ensino ao longo do tempo, foram necessárias as seguintes agregações, relativas ao ensino fundamental:

- as pessoas que concluíram, com aprovação, séries dos graus elementar ${ }^{7} \mathrm{e}$ médio do $1^{0}$ ciclo, ${ }^{8}$ de acordo com o censo de 1970, foram agregadas na categoria fundamental;

- as pessoas que concluíram, com aprovação, séries dos graus primário ou elementar ${ }^{9}$ e ginásio ou médio do $1^{\circ}$ ciclo, ${ }^{10}$ de acordo com os censos de 1980 e 1991, foram agregadas na categoria fundamental. O primeiro grau, no Censo de 1991, já correspondia às oito séries do ensino fundamental.

\section{Educação alcançada no período 1970-2000}

Nas Tabelas 1 e 2, pode-se observar que, entre 1970 e 2000, houve melhoria no nível de educação concluída em todos os grupos de idades e tanto para homens quanto para mulheres. Durante esses 30 anos, ocorreu redução significativa na proporção de pessoas incluídas na categoria "nenhuma educação formal", em todos os grupos etários. No entanto, enquanto para os grupos de idades mais elevadas o crescimento da educação formal no período, dado pelo decréscimo na proporção de pessoas com nenhuma instrução formal, parece ter redundado, principalmente, em aumento na proporção daquelas com pelo menos uma série concluída do ensino fundamental, para os grupos etários

\footnotetext{
${ }^{6}$ Sobre as mudanças na organização do sistema educacional brasileiro, veja Rigotti (2004).

${ }^{7}$ Composto de quatro séries, mas existia a possibilidade de o aluno permanecer até seis anos nesse grau, esperando aprovação no exame de admissão para o grau seguinte.

${ }^{8}$ Composto de quatro séries.

${ }^{9}$ Composto de quatro séries, mas existia a possibilidade de o aluno permanecer até seis anos nesse grau, esperando aprovação no exame de admissão para o grau seguinte.

${ }^{10}$ Composto de quatro séries.
} 
TABELA 1

Taxas de educação alcançada pelas mulheres, segundo grupos de idade e graus de ensino Brasil-1970-2000

\begin{tabular}{|c|c|c|c|c|}
\hline \multirow{2}{*}{ Grupos de idade e grau de ensino } & \multicolumn{4}{|c|}{ Em porcentagem } \\
\hline & 1970 & 1980 & 1990 & 2000 \\
\hline \multicolumn{5}{|l|}{ 15-19 anos } \\
\hline Nenhum & 23,66 & 13,76 & 8,37 & 2,72 \\
\hline Fundamental & 70,53 & 72,82 & 69,28 & 81,46 \\
\hline Médio & 5,57 & 12,85 & 20,59 & 14,57 \\
\hline Superior & 0,24 & 0,57 & 1,75 & 1,25 \\
\hline \multicolumn{5}{|l|}{ 20-24 anos } \\
\hline Nenhum & 29,97 & 15,89 & 9,76 & 3,43 \\
\hline Fundamental & 58,78 & 60,26 & 58,30 & 54,01 \\
\hline Médio & 9,09 & 17,48 & 24,07 & 32,64 \\
\hline Superior & 2,15 & 6,37 & 7,87 & 9,92 \\
\hline \multicolumn{5}{|l|}{ 25-29 anos } \\
\hline Nenhum & 35,13 & 19,39 & 10,62 & 4,36 \\
\hline Fundamental & 56,41 & 59,58 & 57,15 & 55,43 \\
\hline Médio & 6,53 & 13,22 & 22,39 & 29,26 \\
\hline Superior & 1,94 & 7,81 & 9,84 & 10,95 \\
\hline \multicolumn{5}{|l|}{ 30-34 anos } \\
\hline Nenhum & 37,96 & 24,37 & 12,75 & 5,81 \\
\hline Fundamental & 55,56 & 59,12 & 58,75 & 57,40 \\
\hline Médio & 5,10 & 9,79 & 18,37 & 25,75 \\
\hline Superior & 1,38 & 6,72 & 10,14 & 11,05 \\
\hline \multicolumn{5}{|l|}{ 35-39 anos } \\
\hline Nenhum & 42,29 & 30,12 & 17,04 & 6,93 \\
\hline Fundamental & 52,71 & 58,36 & 58,79 & 57,76 \\
\hline Médio & 3,91 & 7,01 & 14,52 & 23,43 \\
\hline Superior & 110 & 452 & 965 & 1187 \\
\hline $40-44$ anos & ' & ', & ' & , \\
\hline Nenhum & 45,25 & 34,16 & 22,62 & 8,96 \\
\hline Fundamental & 50,27 & 57,11 & 58,38 & 59,29 \\
\hline Médio & 3,54 & 5,50 & 10,94 & 20,09 \\
\hline Superior & 0,93 & 3,23 & 8,07 & 11,66 \\
\hline \multicolumn{5}{|l|}{ 45-49 anos } \\
\hline Nenhum & 49,71 & 37,95 & 27,96 & 12,64 \\
\hline Fundamental & 46,45 & 54,99 & 58,05 & 60,21 \\
\hline Médio & 3,15 & 4,63 & 8,30 & 16,15 \\
\hline Superior & 0,70 & 2,44 & 5,70 & 11,00 \\
\hline \multicolumn{5}{|l|}{ 50-54 anos } \\
\hline Nenhum & 54,90 & 42,11 & 32,53 & 17,77 \\
\hline Fundamental & 41,60 & 51,87 & 56,90 & 60,79 \\
\hline Médio & 2,94 & 4,18 & 6,75 & 12,54 \\
\hline Superior & 0,56 & 1,84 & 3,81 & 8,90 \\
\hline \multicolumn{5}{|l|}{ 55-59 anos } \\
\hline Nenhum & 56,53 & 47,44 & 37,77 & 23,93 \\
\hline Fundamental & 40,26 & 47,54 & 53,65 & 60,48 \\
\hline Médio & 2,74 & 3,77 & 5,61 & 9,37 \\
\hline Superior & 0,46 & 1,25 & 2,97 & 6,21 \\
\hline \multicolumn{5}{|l|}{ 60-64 anos } \\
\hline Nenhum & 61,81 & 53,11 & 42,05 & 28,51 \\
\hline Fundamental & 35,51 & 42,44 & 50,91 & 59,59 \\
\hline Médio & 2,24 & 3,44 & 4,88 & 7,64 \\
\hline Superior & 0,43 & 1,01 & 2,16 & 4,26 \\
\hline \multicolumn{5}{|l|}{ 65-69 anos } \\
\hline Nenhum & 62,16 & 58,95 & 48,01 & 33,84 \\
\hline Fundamental & 35,41 & 37,32 & 46,11 & 56,46 \\
\hline Médio & 2,10 & 3,04 & 4,26 & 6,52 \\
\hline Superior & 043 & 101 & 216 & 426 \\
\hline
\end{tabular}

Fonte: IBGE. Censos Demográficos de 1970, 1980, 1991 e 2000; elaboração própria.

Nota: No grau nenhum estão incluídas pessoas que não completaram nenhum grau de educação formal; nos demais graus estão incluídas pessoas que completaram pelo menos uma série de cada grau. 
TABELA 2

Taxas de educação alcançada pelos homens, segundo grupos de idade e graus de ensino Brasil - 1970-2000

\begin{tabular}{|c|c|c|c|c|}
\hline \multirow[b]{2}{*}{ Grupos de idade e graus de ensino } & & & \multicolumn{2}{|c|}{ Em porcentagem } \\
\hline & 1970 & 1980 & 1990 & 2000 \\
\hline \multicolumn{5}{|l|}{ 15-19 anos } \\
\hline Nenhum & 26,25 & 18,06 & 12,82 & 4,28 \\
\hline Fundamental & 68,85 & 71,19 & 70,76 & 84,02 \\
\hline Médio & 4,66 & 10,37 & 15,28 & 10,87 \\
\hline Terciário & 0,24 & 0,38 & 1,14 & 0,83 \\
\hline \multicolumn{5}{|l|}{ 20-24 anos } \\
\hline Nenhum & 29,15 & 17,18 & 12,95 & 5,41 \\
\hline Fundamental & 58,78 & 60,26 & 58,30 & 54,01 \\
\hline Médio & 7,53 & 15,80 & 19,75 & 26,65 \\
\hline Terciário & 3,16 & 5,43 & 6,00 & 7,30 \\
\hline \multicolumn{5}{|l|}{ 25-29 anos } \\
\hline Nenhum & 31,67 & 18,75 & 12,88 & 6,66 \\
\hline Fundamental & 59,15 & 61,39 & 58,74 & 60,16 \\
\hline Médio & 5,42 & 11,75 & 19,92 & 24,57 \\
\hline Terciário & 3,77 & 8,11 & 8,46 & 8,61 \\
\hline \multicolumn{5}{|l|}{ 30-34 anos } \\
\hline Nenhum & 32,72 & 22,42 & 13,56 & 8,07 \\
\hline Fundamental & 59,76 & 60,81 & 59,51 & 60,52 \\
\hline Médio & 4,32 & 8,61 & 17,11 & 22,44 \\
\hline Terciário & 3,20 & 8,17 & 9,82 & 8,97 \\
\hline \multicolumn{5}{|l|}{ 35-39 anos } \\
\hline Nenhum & 34,61 & 26,29 & 16,34 & 8,68 \\
\hline Fundamental & 58,71 & 60,55 & 60,13 & 59,59 \\
\hline Médio & 3,67 & 6,47 & 13,35 & 21,53 \\
\hline Terciário & 3,02 & 6,69 & 10,19 & 10,20 \\
\hline \multicolumn{5}{|l|}{$40-44$ anos } \\
\hline Nenhum & 37,29 & 29,22 & 20,30 & 9,87 \\
\hline Fundamental & 56,57 & 60,28 & 60,03 & 60,39 \\
\hline Médio & 3,20 & 5,41 & 10,15 & 18,71 \\
\hline Terciário & 2,94 & 5,10 & 9,52 & 11,02 \\
\hline \multicolumn{5}{|l|}{$45-49$ anos } \\
\hline Nenhum & 40,15 & 31,17 & 24,64 & 12,23 \\
\hline Fundamental & 54,36 & 59,35 & 59,48 & 61,46 \\
\hline Médio & 2,69 & 4,84 & 8,16 & 15,17 \\
\hline Terciário & 2,80 & 4,64 & 7,71 & 11,14 \\
\hline \multicolumn{5}{|l|}{ 50-54 anos } \\
\hline Nenhum & 43,76 & 35,03 & 27,17 & 16,38 \\
\hline Fundamental & 51,70 & 56,64 & 59,69 & 61,63 \\
\hline Médio & 2,09 & 4,24 & 7,00 & 11,90 \\
\hline Terciário & 2,44 & 4,09 & 6,14 & 10,09 \\
\hline \multicolumn{5}{|l|}{$55-59$ anos } \\
\hline Nenhum & 45,63 & 39,81 & 31,46 & 21,06 \\
\hline Fundamental & 49,84 & 53,28 & 57,42 & 61,16 \\
\hline Médio & 1,84 & 3,34 & 5,99 & 9,39 \\
\hline Terciário & 2,68 & 3,56 & 5,13 & 8,39 \\
\hline \multicolumn{5}{|l|}{ 60-64 anos } \\
\hline Nenhum & 49,72 & 44,45 & 36,06 & 25,14 \\
\hline Fundamental & 46,30 & 49,89 & 54,35 & 60,53 \\
\hline Médio & 1,78 & 2,61 & 4,85 & 7,90 \\
\hline Terciário & 2,20 & 3,05 & 4,75 & 6,44 \\
\hline \multicolumn{5}{|l|}{$65-69$ anos } \\
\hline Nenhum & 50,64 & 50,79 & 42,47 & 29,37 \\
\hline Fundamental & 45,24 & 44,19 & 49,67 & 58,28 \\
\hline Médio & 1,73 & 2,13 & 4,00 & 6,79 \\
\hline Terciário & 2,39 & 2,89 & 3,86 & 5,57 \\
\hline
\end{tabular}

Fonte: IBGE. Censos Demográficos de 1970, 1980, 1991 e 2000; elaboração própria.

Nota: No grau nenhum estão incluídas pessoas que não completaram nenhum grau de educação formal; nos demais graus estão incluídas pessoas que completaram pelo menos uma série de cada grau. 
mais jovens teve maior significado a expansão na categoria com alguma série de ensino médio e superior.

Independente do período analisado e do sexo, os grupos de idades mais jovens têm maior proporção de pessoas em graus mais elevados de educação. Em 1970, por exemplo, no grupo de mulheres de 20 a 24 anos, $11,24 \%$ possuíam pelo menos uma série de educação concluída acima do fundamental, contra $3,2 \%$ no grupo etário de 55 a 59 anos (Tabela 1). Em 2000, essas proporções eram de $42,56 \%$ e $15,58 \%$, respectivamente para os dois grupos etários. Esta comparação entre os períodos revela também as modificações ocorridas na distribuição da população por educação que, de altamente concentrada nos meno- res graus em 1970, em todos os grupos etários, passou a apresentar concentração significativa em graus mais elevados de educação em 2000.

Entre os grupos de 15 a 19 e 20 a 24 anos, observam-se expressiva diminuição na proporção de pessoas com até pelo menos uma série concluída de ensino fundamental e aumento para os demais graus, principalmente o médio. Este fato sugere que, apesar de a faixa etária considerada adequada para o ensino fundamental ser entre 7 e 14 anos, uma parcela representativa de pessoas o conclui em idades mais elevadas.

Do ponto de vista dos diferenciais entre os sexos, por grupo etário, a proporção de mulheres na faixa etária inferior a 20-24

\section{GRÁFICO 1}

Proporção de mulheres com nenhuma educação formal, por grupos de idade Brasil - 1970-2000

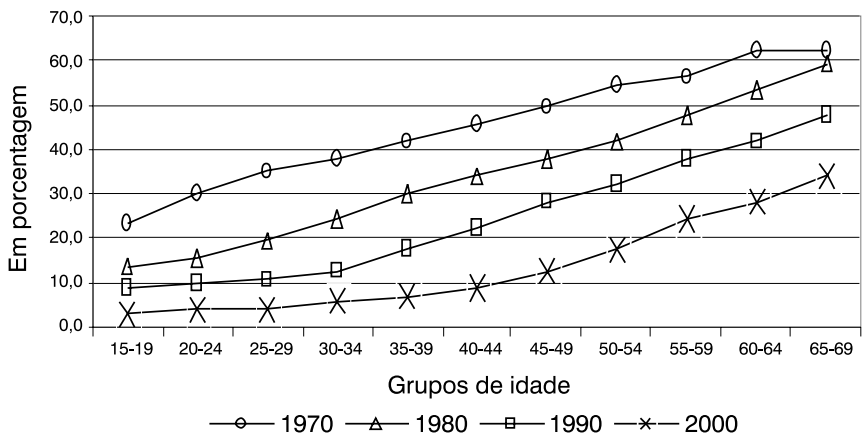

Fonte: IBGE. Censos Demográficos de 1970, 1980, 1991 e 2000; elaboração própria.

GRÁFICO 2

Proporção de mulheres com pelo menos uma série concluída do ensino fundamental, por grupos de idade Brasil-1970-2000

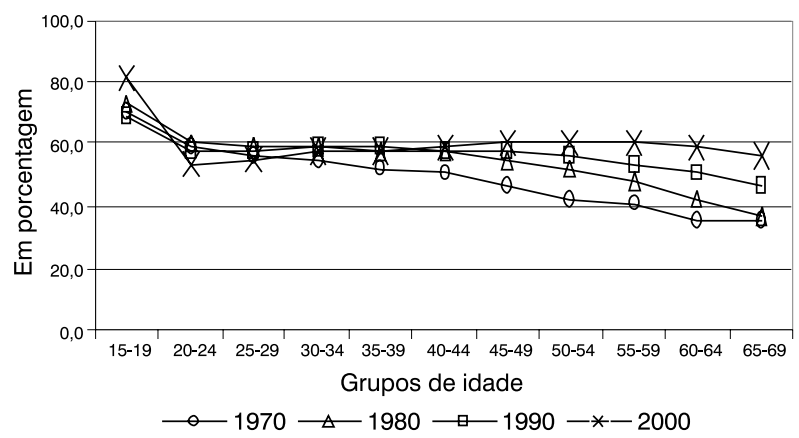

Fonte: IBGE. Censos Demográficos de 1970, 1980, 1991 e 2000; elaboração própria. 
anos que alcançaram os graus educacionais médio e superior, em todos os períodos analisados, é maior que a dos homens. Após este grupo etário, o porcentual de muIheres com educação acima do fundamental fica abaixo daquele verificado para os homens, a partir de: $25-29$ anos, em 1970; 30-34 anos, em 1980; 35-39 anos, em 1990; e 50-54 anos, em 2000. Estes resultados evidenciam que o ingresso das mulheres em graus educativos formais mais elevados foi posterior ao dos homens.

\section{GRÁFICO 3}

Proporção de mulheres com pelo menos uma série concluída do ensino médio, por grupos de idade Brasil - 1970-2000

Fonte: IBGE. Censos Demográficos de 1970, 1980, 1991 e 2000; elaboração própria.

\section{GRÁFICO 4}

Proporção de mulheres com pelo menos uma série concluída de ensino terciário, por grupos de idade Brasil - 1970-2000

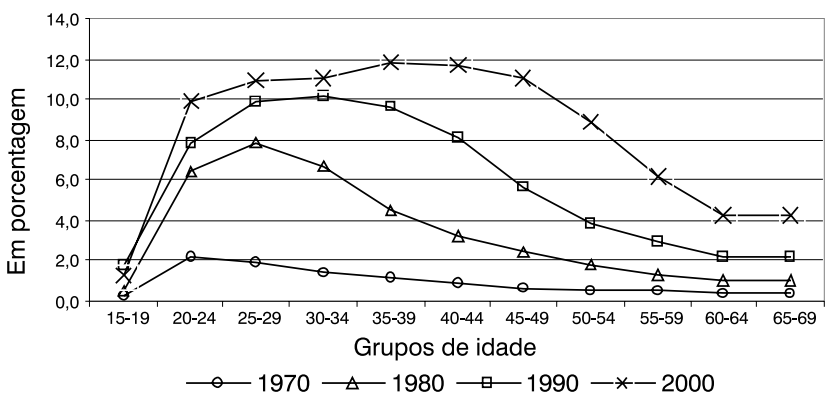

Fonte: IBGE. Censos Demográficos de 1970, 1980, 1991 e 2000; elaboração própria.

GRÁFICO 5

Proporção de homens com nenhuma educação formal, por grupos de idade Brasil - 1970-2000

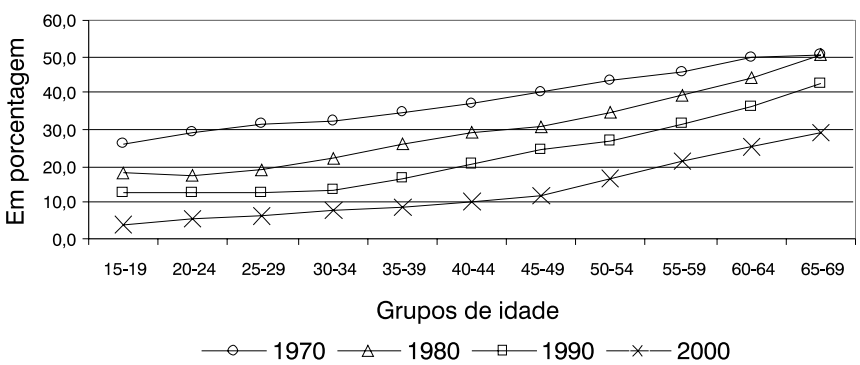

Fonte: IBGE. Censos Demográficos de 1970, 1980, 1991 e 2000; elaboração própria 


\section{GRÁFICO 6}

Proporção de homens com pelo menos uma série concluída de ensino fundamental, por grupos de idade Brasil - 1970-2000

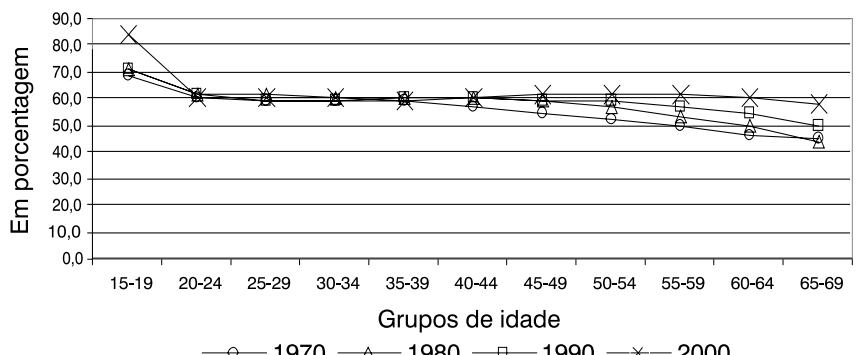

Fonte: IBGE. Censos Demográficos de 1970, 1980, 1991 e 2000; elaboração própria.

GRÁFICO 7

Proporção de homens com pelo menos uma série concluída de ensino médio, por grupos de idade Brasil - 1970-2000

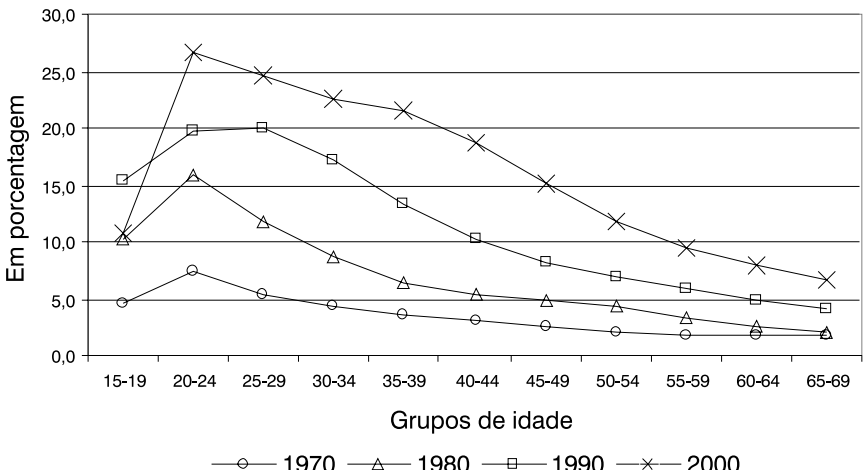

Fonte: IBGE. Censos Demográficos de 1970, 1980, 1991 e 2000; elaboração própria.

GRÁFICO 8

Proporção de homens com pelo menos uma série concluída de ensino terciário, por grupos de idade Brasil - 1970-2000

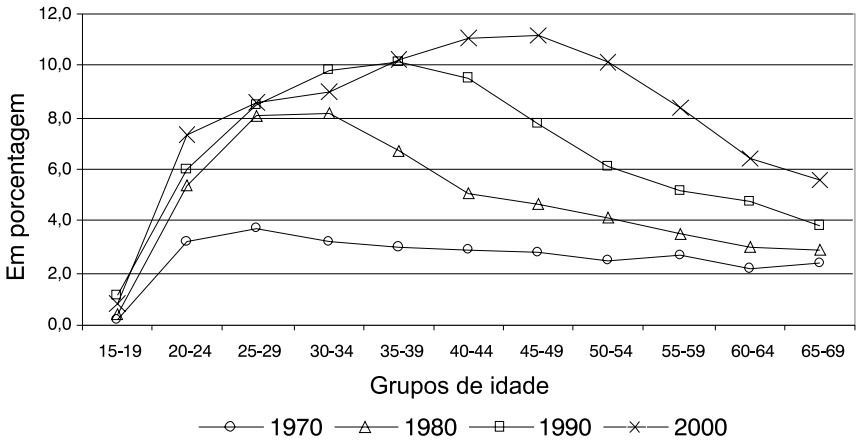

Fonte: IBGE. Censos Demográficos de 1970, 1980, 1991 e 2000; elaboração própria. 
Pode-se considerar que o ponto mais alto das taxas de prevalência no grau escolar, por grupo de idade e ano, indica em que momento a população em questão conclui os estudos em cada nível, ou seja, quando, provavelmente, deixa de ocorrer transição entre os níveis. Assim sendo, verifica-se, nos Gráficos de 1 a 8 , uma mudança no formato das curvas das taxas de prevalência para cada grau escolar, por grupo etário e ano, principalmente para aquelas que descrevem o comportamento dos ensinos médio e superior para 1990 e 2000, sugerindo a ocorrência de maior permanência das pessoas na escola. Com relação ao ensino médio, para os dois anos considerados, a maior proporção de pessoas é verificada no grupo de 20 a 24 anos, mas o crescimento das taxas, em relação ao período anterior, nos grupos etários seguintes, permanece alto e praticamente constante até a faixa de 35 a 39 anos. A proporção de pessoas com pelo menos algum ano completado do nível superior, em 2000, parece estabilizar entre os grupos de 25 a 29 e de 30 a 34 anos, voltando depois a crescer e mantendo valores altos até por volta do grupo etário 45 a 49 anos. Este comportamento da curva sugere que pessoas que já tinham deixado a escola decidiram retornar e alcançaram níveis mais elevados de educação final, provavelmente motivadas pelo mercado de trabalho.

\section{Análise por coorte}

Nos Gráficos 9 a 12 observa-se o comportamento das taxas de prevalência da população, nos graus secundário e terciário de educação, entre 1970 e 2000, por sexo e coorte. Cada linha do gráfico corresponde a uma coorte, definida como a proporção de pessoas do grupo etário que tinha pelo menos um ano de estudo concluído em cada um dos dois graus, em 1970. Assim, em cada gráfico estão representadas oito coortes, uma para cada grupo etário entre 15-19 e 50-54 anos, em 1970. A base de dados é constituída por somente quatro pontos no tempo, com intervalo de dez anos entre eles, referentes às datas dos censos; no entanto, para facilitar o desenho dos gráficos em grupos etários de cinco anos e a comparação entre as coortes, foram alocados mais três pontos, por interpolação.

Conforme os Gráficos de 9 a 12, a proporção de pessoas com pelo menos um ano de educação secundária ou terciária

GRÁFICO 9

Evolução, entre 1970 e 2000, da proporção de mulheres de cada grupo etário com pelo menos uma série concluída no ensino secundário em 1970

Brasil

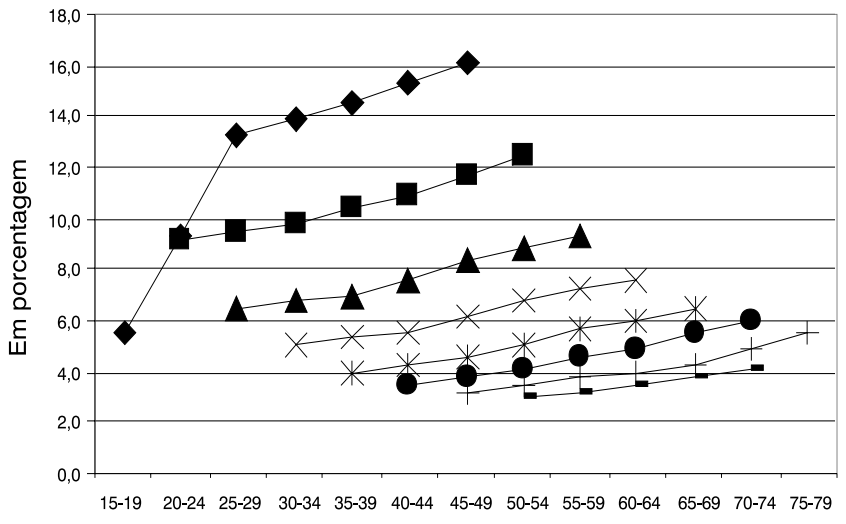

Grupos de idade

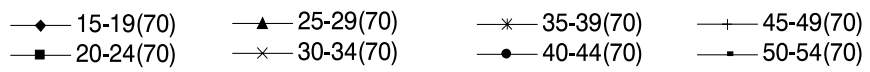

Fonte: IBGE. Censos Demográficos de 1970, 1980, 1991 e 2000; elaboração própria. 


\section{GRÁFICO 10}

Evolução, entre 1970 e 2000, da proporção de mulheres de cada grupo etário com pelo menos uma série concluída no ensino terciário em 1970

Brasil

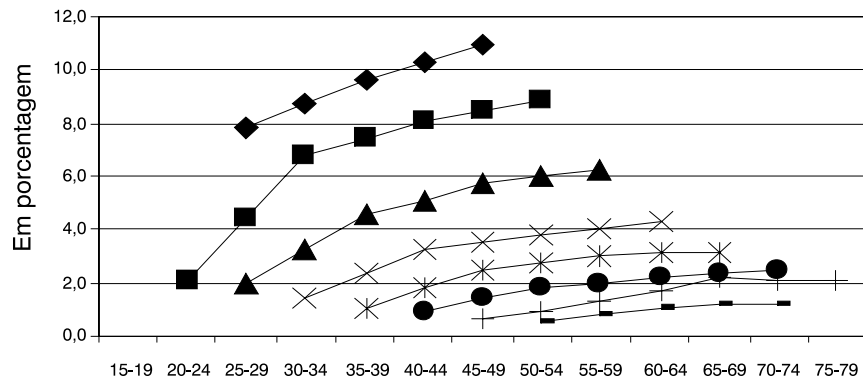

Grupos de idade

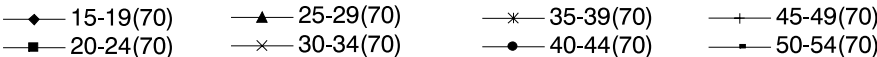

Fonte: IBGE. Censos Demográficos de 1970, 1980, 1991 e 2000; elaboração própria.

GRÁFICO 11

Evolução, entre 1970 e 2000, da proporção de homens de cada grupo etário com pelo menos uma série concluída no ensino secundário em 1970

Brasil

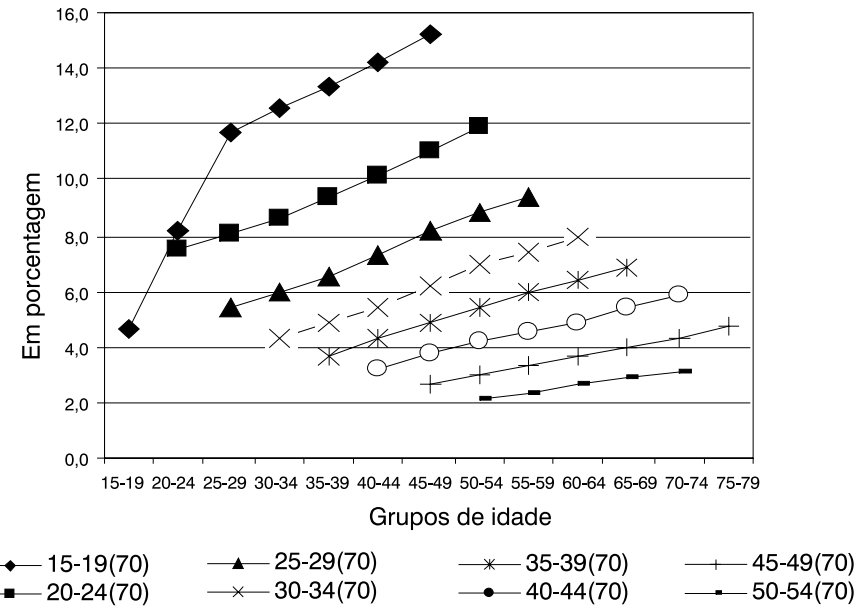

Fonte: IBGE. Censos Demográficos de 1970, 1980, 1991 e 2000; elaboração própria.

cresceu entre todas as coortes e, como esperado, é bem mais alta para as coortes mais jovens. A proporção de mulheres com pelo menos um ano de educação superior é menor que a dos homens em todas as coortes em análise, mas o crescimento pronunciado desse nível de educação entre as coortes de mulheres mais jovens, somado à maior sobrevivência feminina, faz com que a coorte de 15 a 19 anos, em 1970, tenha uma proporção de pessoas de nível superior similar à dos homens em 2000 , quando os membros da coorte atingem 45 a 49 anos. Nesse último ano e grupo de idade, a proporção de homens com pelo menos uma série concluída de ensino superior é $11,14 \%$, contra $11 \%$ de mulheres. A proporção de mulheres com pelo menos uma série concluída de ensino médio é superior à de homens, em todos os pontos 
GRÁFICO 12

Evolução, entre 1970 e 2000, da proporção de homens de cada grupo etário com pelo menos uma série concluída no ensino terciário em 1970

Brasil

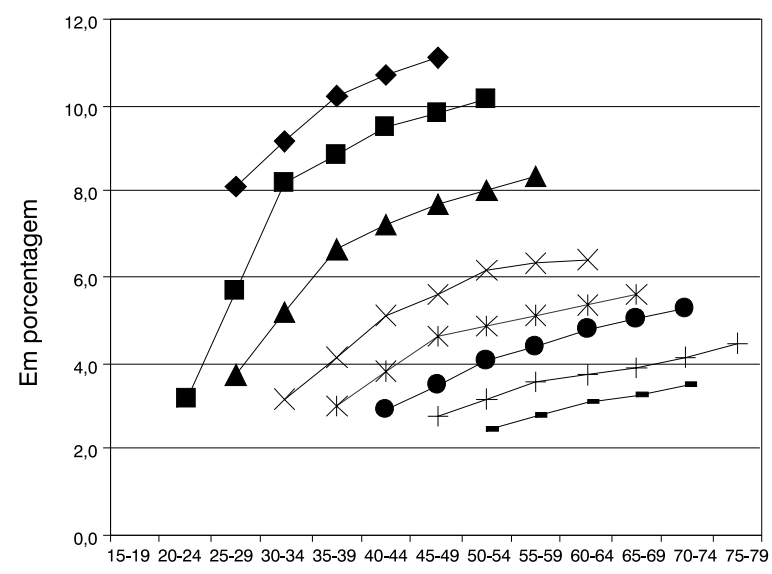

Grupos de idade

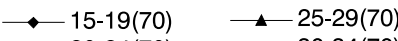

* $35-39(70)$

$+-45-49(70)$

$-20-24(70)$

$\times 30-34(70)$

$\longrightarrow-40-44(70)$

$50-54(70)$

Fonte: IBGE. Censos Demográficos de 1970, 1980, 1991 e 2000; elaboração própria.

no tempo, para as coortes de 15-19 e 20-24 anos, em 1970.

O crescimento das proporções no tempo, para todas as coortes, parece sugerir que transições de níveis de educação mais baixos para outros mais elevados ocorrem até grupos de idades bem avançadas como 70 a 74 anos ou 75 a 79 anos -, para as coortes de 40-44 e 45-49 anos, em 1970. No entanto, conforme visto anteriormente, dado o comportamento das taxas nos períodos, é bem provável que as transições para o grau secundário ocorram até a idade de 35 a 39 anos e, para o nível superior, até 45 a 49 anos. Assim, uma possível explicação para esse comportamento, além, é claro, de problemas decorrentes da qua- lidade dos dados, pode ser encontrada nos diferenciais de mortalidade por educação, resultando em maior proporção de sobreviventes nesses dois graus mais elevados de educação formal, relativamente aos demais.

Neste sentido, a fim de se ter algum indicador da heterogeneidade da mortalidade por educação e sexo no Brasil, foram calculados os diferenciais entre a razão de sobrevivência dos grupos etários de $45-49$ a 60-64 anos, do Censo de 1990, em relação aos grupos 55-59 a 70-74 anos, no Censo de 2000, para os homens, e dos grupos 55-59 a 65-69 anos, em relação aos de 65-69 a 75-79 anos, para as mulheres, por grau de educação. ${ }^{11}$ Sabidamente, esses

\footnotetext{
${ }^{11}$ A razão de sobrevivência entre os outros censos também foi investigada, mas os resultados encontrados para o sexo masculino, entre os períodos 70/80 e 80/90, foram surpreendentes: uma razão de sobrevivência calculada para as pessoas com pelos menos um ano de ensino fundamental menor do que para as pessoas sem educação formal. Para as mulheres, esse comportamento só foi observado para a razão de sobrevivência calculada entre 1970 e 1980. Após algumas análises - dos diferenciais de mortalidade entre as pessoas sem educação formal e aquelas com educação fundamental por setor rural e urbano, em que foi obtido o mesmo resultado, e do comportamento das coortes, que mostrou crescimento na proporção de pessoas sem educação formal nas coortes mais velhas -, levantou-se a hipótese de que pode ter havido melhoria na cobertura para pessoas sem educação formal nos Censos de 80 e 90, o que explicaria os diferenciais na relação de sobrevivência encontrados. As razões de sobrevivência entre os Censos de 1970 e 1980 e os de 1980 e 1990, para o grau superior do sexo feminino, seja porque entre as mulheres mais velhas poucas foram as que atingiram o nível superior de educação formal, seja por outros problemas nos dados, resultaram em valores muito baixos, comparativamente com 90/2000 e o sexo masculino, resultados estes que não pareceram consistentes.
} 
resultados só terão algum valor como indicador de diferenciais de mortalidade se a cobertura for a mesma para todos os censos.

A utilização de grupos de idade mais elevada para construir o estimador de mortalidade por educação objetivou evitar a incorporação do efeito da transição entre os graus de educação, e da migração internacional, no cômputo dos diferenciais de mortalidade. A escolha de grandes grupos etários tem por finalidade minimizar o efeito do erro na declaração de idade entre os mais idosos. Para o segmento masculino, os graus de educação formal que estão sendo comparados são: nenhum; pelo menos uma série concluída do ensino fundamental; e pelo menos uma série concluída do secundário e/ou terciário. ${ }^{12}$ Não foi possível manter essa mesma agregação para a população feminina, uma vez que, provavelmente por problemas nos dados, a razão de sobrevivência calculada para esses graus e agregação foi superior a 1 . Assim, os resultados para as mulheres referem-se a pessoas que concluíram todas as séries do grau.

A comparação entre a razão de sobrevivência calculada conforme descrito anteriormente, para os homens, mostrou que aqueles com pelo menos um ano de estudo concluído do ensino fundamental têm $90 \%$ da sobrevivência daqueles com algum ano de estudo concluído do secundário ou mais e aqueles pertencentes à categoria nenhum grau de educação formal possuem $80 \%$ da sobrevivência. Ou seja, para a população masculina, quanto maior o grau de educação menor a mortalidade. Para as mulheres, no entanto, só parece haver maior mortalidade para aquelas na categoria nenhum grau de educação formal, com uma razão de sobrevivência de $76 \%$ comparativamente à daquelas nos outros graus de educação. Diante desses resultados e considerando-os como indicadores rudimentares, é bem possível que a maior sobrevivência dos que possuem mais escolaridade esteja contribuindo para o crescimento das taxas de prevalência ao longo do tempo dos graus secundário e terciário.

Um outro fator que pode estar influenciando o crescimento ao longo do tempo da proporção de pessoas nos graus mais elevados de educação é a migração internacional. Como tem sido reconhecido por vários autores, o Brasil, depois de permanecer entre 1940 e 1980 praticamente como uma população fechada, passou, a partir de então, a apresentar migração internacional. No caso de a porcentagem de emigrantes, em relação à população em determinado grau de educação, ser maior que aquela relativa à população em qualquer outro grau, sendo tudo o mais constante, fará com que a proporção de pessoas daquele grau educacional com maior porcentagem de emigrantes, no próximo censo, seja menor que a do censo precedente, e a proporção do grau com menor porcentagem de emigrantes, maior que a precedente. O mesmo raciocínio, no sentido inverso, se aplica para os imigrantes.

Conforme estimado por Carvalho (1996), na década de 80 o Brasil perdeu entre 1 e 2 milhões e meio de pessoas através de migração internacional. Como não dispomos de informações sobre a distribuição por educação desses migrantes, fica difícil estabelecer, neste momento, até mesmo o sentido do efeito dessa perda de população nas taxas de prevalência da população por educação.

\section{Efeito da imigração nas taxas de prevalência por educação}

\section{(1996):}

Como adverte José Alberto Carvalho

os fluxos migratórios internacionais no Brasil, com boa parte de seus componentes em ambos os sentidos, constituindo-se no que se convencionou chamar de "ilegais" ou "clandestinos", e com a ausência de registro sistemático, pelo país, das entradas e saídas

\footnotetext{
${ }^{12}$ Estudos preliminares mostraram que não existem diferenciais significativos entre a razão de sobrevivência das pessoas com grau secundário e superior.
} 
de nacionais, as informações diretas, de natureza administrativa ou censitária, sobre emigrantes e imigrantes estão longe de ter a cobertura necessária para se estimar, com grau de confiabilidade necessário o saldo migratório internacional. Não se nega, no entanto, sua importância para análises de tipo mais qualitativo.

Apesar das limitações apontadas, como não estão disponíveis estimativas indiretas dos movimentos migratórios internacionais por grau de educação e, ainda, sabendo-se que os "ilegais" ou "clandestinos" poderão ter uma participação significativa e uma distribuição por educação completamente diferente dos imigrantes legais, podendo invalidar os resultados, resolveu-se assim mesmo investigar a distribuição dos imigrantes internacionais por educação, com base nos Censos de 1991 e 2000.

Esta análise justifica-se uma vez que o impacto da imigração nas taxas de prevalência depende mais de como os imigrantes estão distribuídos por educação do que de seu número. Se a distribuição dos imigrantes estiver mais concentrada nos graus mais elevados de educação, o impacto será maior, pois as taxas de prevalência da população residente são menores nesses graus. Além disso, RiosNeto (2005, p.13) argumenta: "It is hard to conceive the idea of finding a flow on undocumented (illegal) skilled migrants". Levando isso em conta, os resultados aqui apresentados podem ser vistos como um cenário otimista do efeito da imigração sobre as taxas por educação, uma vez que se deve esperar que os imigrantes legais estejam mais concentrados nos graus mais altos de educação que a imigração total.

Procurou-se, então, investigar como os imigrantes registrados nos Censos de 1991 e 2000, dado sua distribuição por educação e sexo, influenciam as taxas de prevalência da população brasileira por grau de educação e sexo.

Nesse sentido, o que se pretende analisar ao final é a relação:

(1) $\left[\left(\right.\right.$ Pop $\left._{i}+X_{i}\right) /\left(\right.$ PopT + I)] / [ Pop $_{i} /$ PopT $]$ onde:
Pop $_{\text {i }}=$ população na data do censo com pelo menos uma série concluída do grau $i$ de educação exclusive dos imigrantes;

$\mathrm{X}_{\mathrm{i}}=$ número de imigrantes na data do censo com pelo menos uma série concluída de grau $i$;

I = número total de imigrantes na data do censo;

PopT $=$ população total exclusive os imigrantes na data do censo.

A imigração não afetará as taxas caso a relação acima seja 1; diminuirá as taxas se a relação for menor que 1; e aumentará se for maior que 1.

Pode-se escrever o numerador da relação (1) como:

(2) Pop $_{\mathrm{i}} /\left(\right.$ PopT + I) $+\mathrm{X}_{\mathrm{i}} /($ PopT + I)

Assim, percebe-se que a imigração afetará as taxas sempre que a proporção de imigrantes, em um determinado grau de educação, em relação à população total, for diferente da queda na proporção da população não-migrante do grau, ocasionada pelo aumento na população total (denominador) devido à agregação dos imigrantes. Mais especificamente, sempre que:

(3) $X_{\mathrm{I}} /\left(\right.$ PopT + I) $\neq$ Pop $_{\mathrm{i}} /$ PopT - Pop $_{\mathrm{i}} /($ PopT + I) ou seja, se:

(4) $\mathrm{X}_{\mathrm{i}} /\left(\right.$ PopT + I) < Pop $_{\mathrm{i}} /$ PopT - Pop $_{\mathrm{i}} /($ PopT + I)

Então, as taxas da população nãomigrante em um dado período diminuirão em conseqüência da imigração.

\section{$\mathrm{Se}$}

(5) $X_{\mathrm{i}} /\left(\right.$ PopT + I) $>$ Pop $_{\mathrm{i}} /$ PopT - Pop $/$ / (PopT + I)

Então a imigração contribuirá para o aumento das taxas da população nãomigrante.

Obviamente, dado um total "I" de imigrantes, o número de imigrantes necessário para manter constante as taxas de prevalência em cada nível de educação seria dado por:

$X_{i}=\left[\right.$ Pop $_{i}$ * (PopT + I) - Pop ${ }_{i}{ }^{*}$ PopT $] /$ PopT

$=$ Pop $_{i} /$ Popt $*$ I 
TABELA 3

Imigrantes registrados nos censos, por sexo, segundo algumas medidas e grau de ensino Brasil-1991-2000

\begin{tabular}{|c|c|c|c|c|}
\hline \multirow{3}{*}{ Medidas e graus de ensino } & \multirow{2}{*}{\multicolumn{2}{|c|}{1991}} & \multirow{2}{*}{\multicolumn{2}{|c|}{$\begin{array}{l}\text { Em porcentagem } \\
2000\end{array}$}} \\
\hline & & & & \\
\hline & Homens & Mulheres & Homens & Mulheres \\
\hline \multicolumn{5}{|l|}{ I Distribuição por grau de educação } \\
\hline Nenhum & 4,18 & 6,19 & 9,59 & 8,58 \\
\hline Fundamental & 24,47 & 28,56 & 57,44 & 57,00 \\
\hline Médio & 25,56 & 29,49 & 19,22 & 22,05 \\
\hline Terciário & 45,79 & 35,76 & 13,75 & 12,38 \\
\hline \multicolumn{5}{|l|}{$\begin{array}{l}\text { II Proporção de imigrantes em relação à } \\
\text { população total (inclusive imig.) }\end{array}$} \\
\hline Nenhum & 0,005 & 0,004 & 0,087 & 0,078 \\
\hline Fundamental & 0,027 & 0,026 & 0,524 & 0,521 \\
\hline Médio & 0,028 & 0,027 & 0,175 & 0,202 \\
\hline Terciário & 0,051 & 0,048 & 0,125 & 0,113 \\
\hline \multicolumn{5}{|l|}{$\begin{array}{l}\text { III Distribuição dos imigrantes que } \\
\text { manteria as taxas constantes (1) }\end{array}$} \\
\hline Nenhum & 0,021 & 0,018 & 0,103 & 0,103 \\
\hline Fundamental & 0,067 & 0,053 & 0,582 & 0,555 \\
\hline Médio & 0,015 & 0,014 & 0,160 & 0,182 \\
\hline Terciário & 0,007 & 0,006 & 0,068 & 0,075 \\
\hline \multicolumn{5}{|l|}{$\begin{array}{l}\text { IV Proporção da pop. não-migrante em } \\
\text { relação à pop. total (inclusive imig.) }\end{array}$} \\
\hline Nenhum & 19,26 & 19,84 & 11,24 & 11,25 \\
\hline Fundamental & 60,45 & 58,16 & 63,70 & 60,61 \\
\hline Médio & 13,73 & 15,65 & 17,52 & 19,93 \\
\hline Terciário & 6,57 & 6,35 & 7,54 & 8,20 \\
\hline \multicolumn{5}{|c|}{$\begin{array}{l}\text { V Proporção da pop. não-migrante em } \\
\text { relação à pop. total (exclusive os imig.) }\end{array}$} \\
\hline Nenhum & 19,27 & 19,85 & 11,26 & 11,28 \\
\hline Fundamental & 60,49 & 58,19 & 63,75 & 60,64 \\
\hline Médio & 13,72 & 15,63 & 17,50 & 19,92 \\
\hline Terciário & 6,52 & 6,33 & 7,49 & 8,16 \\
\hline \multicolumn{5}{|l|}{$\begin{array}{l}\text { VI Variação nas proporções em } \\
\text { decorrência da imigração (IV-V) }\end{array}$} \\
\hline Nenhum & $-0,086$ & $-0,063$ & $-0,135$ & $-0,219$ \\
\hline Fundamental & $-0,066$ & $-0,047$ & $-0,090$ & $-0,055$ \\
\hline Médio & 0,095 & 0,081 & 0,089 & 0,098 \\
\hline Terciário & 0,664 & 0,426 & 0,764 & 0,472 \\
\hline \multicolumn{5}{|l|}{$\begin{array}{l}\text { VII Número de imigrantes que manteria } \\
\text { as taxas constantes (2) }\end{array}$} \\
\hline Nenhum & 9575 & 8644 & 59614 & 63431 \\
\hline Fundamental & 30054 & 25335 & 337620 & 341090 \\
\hline Médio & 6815 & 6807 & 92694 & 112016 \\
\hline Terciário & 3241 & 2755 & 39640 & 45917 \\
\hline Total & 49685 & 43540 & 529568 & 562454 \\
\hline
\end{tabular}

Fonte: IBGE. Censos Demográficos de 1970, 1980, 1991 e 2000; elaboração própria.

(2) Caso este fosse o número absoluto de migrantes em cada grau de educação, a imigração não teria efeito sobre as taxas de prevalência.

Ou seja, a proporção da população não-migrante no grau de educação, multiplicada pelo número total de imigrantes.

$\mathrm{Na}$ Tabela 3 estão os resultados das medidas detalhadas anteriormente, relativas aos imigrantes registrados pelos Censos de
1991 e 2000, por sexo. O item I refere-se à distribuição destes imigrantes por grau de ensino, podendo-se perceber que aqueles registrados em 1991 estão concentrados nos graus mais altos de educação do que os de 2000. No item II, observa-se o resul- 
tado da segunda relação da equação (2), ou seja, a proporção de migrantes em relação à população total. No item III, está registrada a proporção de imigrantes que manteria constante as taxas de prevalência, o resultado da equação (3), ou seja, a distribuição neutra, aquela que, caso ocorresse, faria com que a imigração não provocasse impacto nas taxas de prevalência da população residente. No item IV, observam-se as taxas de prevalência por educação da população residente, tendo por denominador a população residente somada aos imigrantes, ou seja, as taxas computando o efeito da imigração, e, no item $\mathrm{V}$, as mesmas taxas na hipótese de que não tivesse havido migração. A variação na proporção de pessoas em cada grau de ensino em decorrência da imigração é dada no item VI.

Os imigrantes internacionais legais registrados no Censo de 1991 (93.225 pessoas) representaram uma parcela pequena da população com mais de 15 anos $(0,10 \%)$, sendo $53,3 \%$ homens e $46,7 \%$ mulheres e altamente concentrados nos graus mais elevados de educação (primeiro item Tabela 3). Quando comparados os itens II e III da Tabela 3, percebe-se que a distribuição dos imigrantes por grau de educação favorece o aumento das taxas nos níveis mais elevados de educação (médio e superior), já que nesses níveis a proporção de migrantes (item II) é superior àquela que manteria constante as taxas, em que o impacto da imigração sobre as taxas de prevalência da população residente seria nulo (item III).

Já os imigrantes registrados em 2000 , mais numerosos do que os de 1991, representaram $0,94 \%$ da população e, apesar da sua distribuição por grau de educação completamente diferente da daqueles registrados em 1991 e altamente concentrada no ensino fundamental, as conclusões em relação à influência sobre as taxas de prevalência da população não migrante são as mesmas: a imigração favoreceu o aumento das taxas dos graus mais elevados de educação e a diminuição nos mais baixos. Este comportamento decorre do fato de que a proporção de imigrantes registrados em 2000, nos graus mais elevados de educação, é maior que a mesma proporção para a população não-migrante e menor nos graus "nenhum" e fundamental. Por exemplo, do total de imigrantes do sexo feminino, $12,38 \%$ têm pelo menos alguma série concluída do ensino superior (item I), enquanto a mesma proporção para a população não-migrante é de $8,16 \%$ (item V).

Assim, pode-se concluir, observando o item VI da tabela, que a imigração legal, apesar das diferenças na distribuição por educação entre os períodos e em relação à população residente, teve um impacto muito pequeno nas taxas de prevalência por educação. Além disso, diante dos níveis de imigração em relação ao tamanho da população brasileira, dificilmente poder-seia esperar um grande impacto.

\section{Efeito da mudança na estrutura etária no grau de educação concluída}

As taxas totais de educação por grau (TETi) são dadas por:

$\mathrm{TET}_{i}=\mathrm{PoP}_{\mathrm{i}} / \mathrm{PoPT}=\sum_{n} \mathrm{PoP}_{\mathrm{ix}} / \mathrm{PoP}_{\mathrm{x}}{ }_{n}{ }_{n} \mathrm{PoP}_{\mathrm{x}} / \mathrm{PoPT}$ $=\sum_{n} \mathrm{TE}_{\mathrm{ix}}{ }^{*}{ }_{\mathrm{n}} \mathrm{C}_{\mathrm{ix}}$

onde:

$\mathrm{PoP}_{\mathrm{i}}=$ número de pessoas com pelo menos uma série concluída do grau i de educação;

PoPT = população total;

${ }_{n} \mathrm{PoP}_{\mathrm{ix}}=$ número de pessoas no grupo etário $\mathrm{x}$ a $\mathrm{x}+\mathrm{n}$ com pelo menos uma série concluída do grau $\mathrm{i}$;

${ }_{n} \mathrm{PoP}_{\mathrm{x}}=$ número de pessoas no grupo etário $\mathrm{x}$ a $\mathrm{x}+\mathrm{n}$;

${ }_{n} \mathrm{TE}_{\mathrm{ix}}=$ taxa de educação por grupo etário:

${ }_{n} C_{x}=$ distribuição da população por grupos de idade.

Ou seja, é a média ponderada das taxas de educação dos grupos etários onde os pesos são dados pela distribuição da população por grupos de idade.

Entre 1970 e 2000, as taxas de educação por grau da população total mudaram bastante, para os dois sexos, registrando diminuição na proporção de pessoas sem educação formal e crescimento em todos os demais graus (Tabela 4). No entanto, a estrutura etária da população também mudou, mostrando-se mais envelhecida, 
TABELA 4

Proporção de pessoas com última série concluída em cada um dos graus, segundo sexo Brasil - 1970-2000

\begin{tabular}{ccccc} 
& & & & Em porcentagem \\
\hline Sexo & Nenhum & Fundamental & Médio & Terciário \\
\hline $\begin{array}{c}\text { Mulheres } \\
1970\end{array}$ & 39,44 & 54,35 & & 1,06 \\
1980 & 28,08 & 58,26 & 9,14 & 3,83 \\
1990 & 19,84 & 58,16 & 15,65 & 6,35 \\
2000 & 11,25 & 60,61 & 19,93 & 8,20 \\
Homens & & & & 2,49 \\
1970 & 34,83 & 58,41 & 4,27 & 4,75 \\
1980 & 25,89 & 60,66 & 8,70 & 6,57 \\
1990 & 19,26 & 60,45 & 13,73 & 7,54 \\
2000 & 11,24 & 63,70 & & 7,52 \\
\hline
\end{tabular}

Fonte: IBGE. Censos Demográficos de 1970, 1980, 1991 e 2000; elaboração própria.

GRÁFICO 13

Distribuição da população feminina, por grupos de idade Brasil - 1970-2000

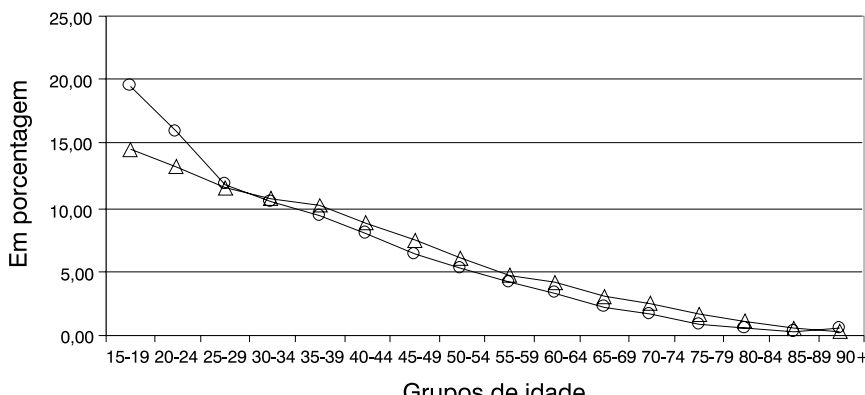

Grupos de idade

$1970 \triangle \triangle-2000$

Fonte: IBGE. Censos Demográficos de 1970, 1980, 1991 e 2000; elaboração própria.

GRÁFICO 14

Distribuição da população masculina, por grupos de idade Brasil - 1970-2000

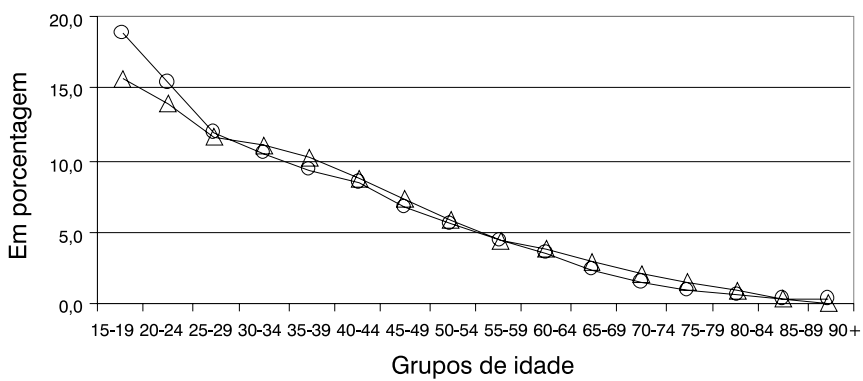

1970 2000

Fonte: IBGE. Censos Demográficos de 1970, 1980, 1991 e 2000; elaboração própria. 
como se pode observar nos Gráficos 13 e 14. Considerando que a melhoria nos graus de educação, como discutido anteriormente, foi mais acentuada nos grupos etários mais jovens, será analisado agora quanto da diferença entre as taxas de prevalência por grau de educação no período pode ser atribuído à mudança na estrutura etária da população e quanto à mudança nas taxas de educação; em síntese, decompor os efeitos.

A expressão usada aqui para decompor a diferença $(\Delta)$ entre as taxas será: ${ }^{13}$

$\Delta=\mathrm{TET}_{\mathrm{i}}{ }^{\mathrm{A}}-\mathrm{TET}_{\mathrm{i}}^{\mathrm{B}}=\sum_{\mathrm{n}} \mathrm{TE}_{\mathrm{ix}}{ }^{\mathrm{A}}{ }_{\mathrm{n}} \mathrm{Ci}_{\mathrm{x}}{ }^{\mathrm{A}}-\sum_{\mathrm{n}} \mathrm{TE}_{\mathrm{ix}}{ }^{\mathrm{B}}{ }_{\mathrm{n}} \mathrm{C}_{\mathrm{x}}{ }^{\mathrm{B}}$ $\left.=\sum\left({ }_{n} C_{i x}{ }^{B}-{ }_{n} C_{i x}{ }^{A}\right)\right]^{*}\left[\left({ }_{n} T E_{i x}{ }^{A}+{ }_{n} T E_{i x}{ }^{B}\right) / 2\right]+$ $\sum\left({ }_{n}{ }^{T} E_{i x}{ }^{B}-{ }_{n}{ }^{T} E_{i x}{ }^{A}\right)^{*}\left[\left({ }_{n} C_{i x}{ }^{B}+{ }_{n} C_{i x}{ }^{A}\right) / 2\right]$

Onde o primeiro termo da adição computa a contribuição para a diferença entre as taxas de $A$ e $B$, que pode ser atribuída à mudança na distribuição da população por grupo de idade, quando a padrão é a média das taxas por educação de $\mathrm{A}$ e $\mathrm{B}$ e, o segundo, aquela atribuída à mudança nas taxas por educação, quando a padrão é a média da distribuição por idade de $A$ e $B$.

Os resultados da decomposição podem ser vistos na Tabela 5, para mulheres e homens. Comparando a primeira linha das medidas relativas a cada sexo, percebe-se que a melhoria na educação das mulheres, no período, foi maior que a dos homens. A diferença entre 2000 e 1970 na proporção de pessoas sem educação formal, por exemplo, foi de $-28,19$, para as mulheres, e de $-23,59$, para os homens, na de pessoas com pelo menos alguma série concluída de ensino fundamental correspondeu a, respectivamente, 6,26 e 5,29, na daquelas com pelo menos alguma série concluída do ensino médio a 14,8 e 13,25 e na de pessoas com pelo menos alguma série concluída do ensino superior a 7,14 e 5,06 .

Para todos os graus de educação a componente mais importante para explicar a melhoria dos níveis educacionais da população brasileira, representada pela variação das taxas entre os períodos, é a própria mudança nas taxas específicas. Para os graus "nenhuma, fundamental e médio", a mudança nas taxas explica mais de $100 \%$ da mudança, para os dois sexos. Para o nível superior explica $0,99 \%$, para as mulheres, e $0,97 \%$, para os homens (última linha da Tabela 5 , relativa a cada sexo).

A parte da diferença entre as taxas por educação devida ao efeito da mudança na estrutura etária, entre 1970 e 2000, depende do grau que se está analisando. Para "nenhuma educação formal", como a proporção de pessoas nessa situação vem diminuindo ao longo do tempo, as taxas são mais elevadas nas idades mais altas. Assim, a estrutura etária mais envelhecida tende a aumentar a taxa total desse grau em 2000 , contribuindo para diminuir a queda observada nas taxas entre os dois períodos. $A$ variação total negativa $(-28,19$, para muIheres, e -23,59, para os homens) e a contribuição para a variação total dada pela diferença entre as taxas nesse grau no período $(-30,19$, para mulheres, e $-24,44$, para homens) sinalizam a queda da proporção de pessoas com nenhuma educação formal no período. A contribuição para a variação total dada pela diferença entre as distribuições por idade dos dois períodos, por outro lado, é positiva, apontando para um aumento de 2 e 0,85 na proporção de pessoas com nenhuma educação formal, para mulheres e homens, respectivamente. De fato, se não tivesse havido mudança na distribuição da população por idade entre 1970 e 2000, as taxas de prevalência nesse grau educacional em 2000 seriam ainda mais baixas, e a diferença entre as taxas dos dois períodos, maior (Tabela 5).

Com relação aos graus fundamental e médio, as duas componentes da diferença entre as taxas de 1970 e 2000 , estrutura etária e taxa, também têm sentido contrário. No entanto, de forma distinta do fundamental, as diferenças entre as taxas são positivas, ou seja, o efeito ao final do período foi aumento na proporção de pessoas com pelo menos alguma série concluída nesses

${ }^{13}$ Para maiores detalhes ver Preston et al. (2001, p.28-29) 
graus de educação. A decomposição (Tabela 5) mostra que a contribuição para as diferenças desses dois níveis no período, dada pelo envelhecimento da população, é negativa e, assim sendo, atua no sentido de diminuir a diferença total do período. Por sua vez, a contribuição para a diferença, dada pela diferença entre as taxas específicas por educação dos dois períodos, é positiva, e maior que a diferença total. Dito de outra forma, as TET 2000 desse dois graus poderiam ser maiores caso não tivesse havido mudança na estrutura por idades da população. $O$ efeito da mudança na distribuição da população é maior no grau fundamental do que no médio, já que a primeira população tende a ser mais jovem que a segunda.

Com relação ao nível superior, como a população com esse grau de educação também é mais velha, as duas componentes atuam no mesmo sentido, aumentando a diferença entre os dois períodos.

Entre os graus, o efeito da mudança na estrutura etária é mais pronunciado no fundamental $(-25 \%$ e $-16 \%$ da taxa, para mulheres e homens, respectivamente), dado ser este o grau com concentração de pessoas em idades mais baixas.

$\mathrm{Na}$ Tabela 6 observa-se o quanto da diferença entre as taxas por educação entre mulheres e homens, em 2000, decorre da diferença entre suas estruturas etárias e/ ou da diferença entre as próprias taxas. Em
2000, conforme a Tabela 4, a proporção total de mulheres com pelo menos um ano de educação concluído nos graus médio e superior é maior do que a dos homens e a daquelas com pelo menos um ano de educação no ensino fundamental é menor. Assim, a diferença entre as taxas totais é positiva para os graus mais elevados e negativa para o menor grau em análise (ver primeira linha da Tabela 6).

A estrutura etária mais envelhecida das mulheres em relação à dos homens com pelo menos uma série concluída do ensino fundamental (Gráfico 15) é responsável por $11 \%$ da diferença entre as taxas de homens e mulheres em 2000 nesse nível. No entanto, como as mulheres aumentaram sua participação nos graus médio e superior mais recentemente, sua estrutura etária, nesses graus, é mais jovem que a dos homens (Gráficos 16 e 17), e a contribuição para a diferença total entre as taxas dada pela diferença entre as estruturas etárias de homens e mulheres é negativa, diminuindo, assim, a diferença total entre as taxas. Dessa forma, se elas tivessem a mesma distribuição por idades nesses níveis que a dos homens, elas teriam taxas de prevalência ainda mais elevadas.

Conforme a última linha da Tabela 6, a componente que explica entre $89 \%$ e mais de $100 \%$ da diferença entre as taxas por educação entre homens e mulheres, em 2000, é a própria taxa por educação.

GRÁFICO 15

Proporção de homens e mulheres com pelo menos uma série concluída do ensino fundamental, segundo grupos de idade

Brasil-2000

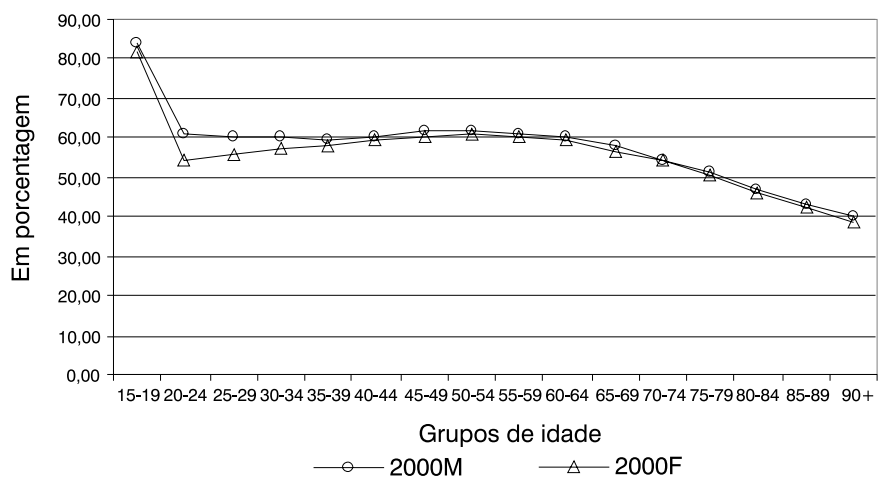

Fonte: IBGE. Censos Demográficos de 1970, 1980, 1991 e 2000; elaboração própria. 
GRÁFICO 16

Proporção de homens e mulheres com pelo menos uma série concluída do ensino médio, segundo grupos de idade Brasil - 2000

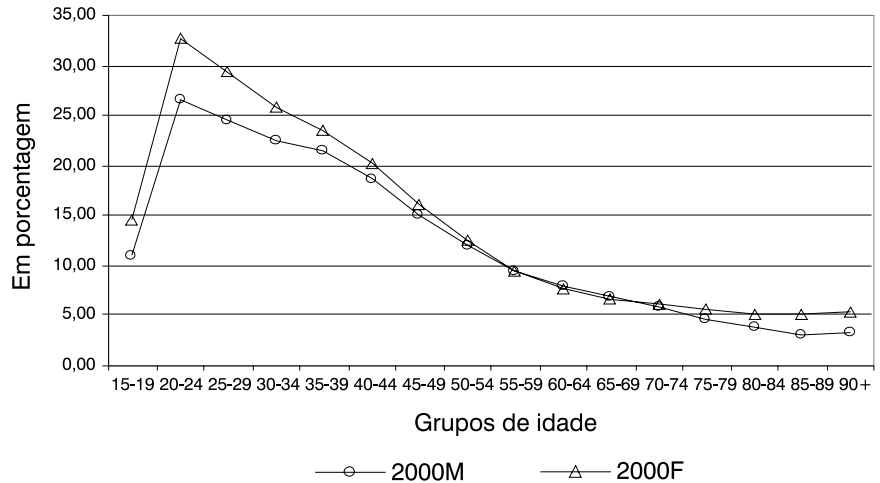

Fonte: IBGE. Censos Demográficos de 1970, 1980, 1991 e 2000; elaboração própria.

GRÁFICO 17

Proporção de homens e mulheres com pelo menos uma série concluída do ensino superior, segundo grupos de idade Brasil-2000

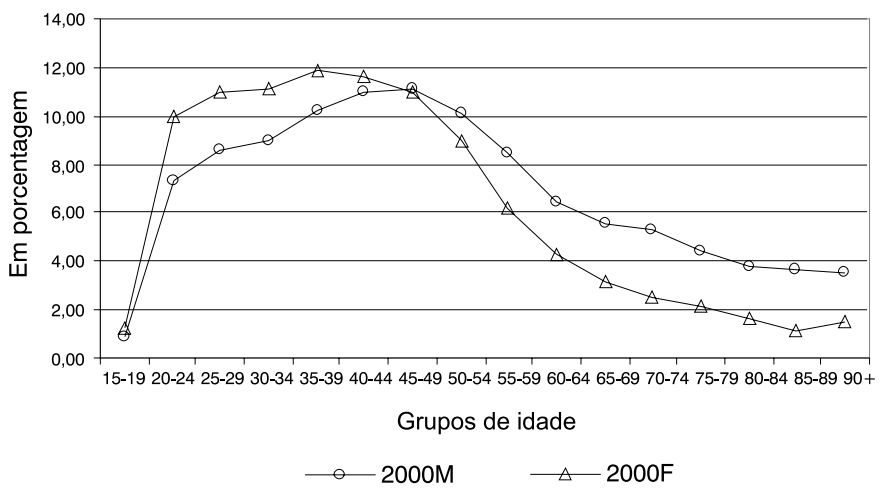

Fonte: IBGE. Censos Demográficos de 1970, 1980, 1991 e 2000; elaboração própria.

\section{Conclusão}

Neste trabalho foram analisadas as mudanças ocorridas nas taxas de prevalência por educação de pessoas com nenhuma educação formal e daquelas com pelo menos uma série concluída nos graus fundamental, médio ou secundário, e superior ou terciário, por sexo, durante o período de 1970 a 2000.

Observa-se que, nestes 30 anos, houve redução expressiva na proporção de pessoas com nenhuma educação formal em todos os grupos etários, para os dois sexos.
No entanto, se para os grupos de idades mais elevadas o crescimento da educação formal parece ter resultado em aumento na porcentagem de pessoas com pelo menos uma série concluída do grau fundamental, para os grupos etários mais jovens o crescimento na proporção de pessoas com ensinos médio e superior é mais significativa. Em conseqüência, a análise das curvas de taxas de prevalência nos graus médio e superior, por grupo etário e ano, sugere uma maior permanência na escola para os anos de 1990 e 2000 , relativamente aos demais. 
A análise por coorte mostrou que, apesar da participação das mulheres nos graus mais elevados de educação ser posterior à dos homens, o crescimento da participação da coorte de 15 a 19 anos em 1970 , no nível de educação superior, somado à sua maior sobrevivência, fez com que em 2000 homens e mulheres tivessem praticamente a mesma proporção. Para o ensino médio, a proporção de mulheres nas duas coortes mais jovens, 15-19 e 20-24 anos, já era superior à dos homens em 1970.

Além disso, análises preliminares sobre diferenciais de mortalidade e imigração por educação evidenciaram a importância, principalmente da primeira dessas variáveis, no estudo do crescimento das taxas de prevalência, por grau de educação.

Quando comparadas as diferenças entre as taxas de 1970 e 2000, por grau de educação, de homens e mulheres, verificase que as taxas relativas às mulheres registraram alteração maior que a dos homens. Observa-se, também, que pequena parte dessa diferença pode ser atribuída à mudança na estrutura etária da população brasileira. A estrutura etária mais envelhecida em 2000 tendeu a diminuir a diferença entre as taxas de 2000 e 1970 dos níveis

\section{Referências bibliográficas}

BARRO, R.; LEE, J. W. International comparison of educational attainment. Journal of Monetary Economics, v.32, p.363-394, 1993.

International data on educational attainment updates and implications. Cambridge, MA, USA, National Bureau of Economic Research, 2000 (NBER Working Paper, 7911).

BELTRÃO, K.I.; ALVES, J.E.D. A reversão do hiato de gênero na educação brasileira no século XX. ENCONTRO NACIONAL DE ESTUDOS POPULACIONAIS, 14, Caxambu, 2004. Anais... Belo Horizonte: ABEP, 2004.

BORJAS, G. J. The economics of immigration. Journal of Economic Literature, Nashiville, Tennessee, v. 32, p.1667-1717, 1994. nenhuma educação formal, fundamental e médio, mas o impacto nas taxas de 2000 não é o mesmo nos três graus. Como a proporção de pessoas sem educação formal decresceu no tempo, as maiores taxas estão concentradas entre os mais velhos. Assim sendo, a contribuição da mudança na estrutura etária para diferença entre as taxas é positiva e, como a diferença entre as taxas de 2000 e 1970 é negativa, a mudança na estrutura etária tem o efeito de diminuir a diferença entre as taxas no período. Podese dizer, então, que se não tivesse havido mudança na distribuição etária da população, a taxa em 2000 seria ainda menor. Para os ensinos fundamental e médio, como a diferença é positiva e as maiores taxas concentradas em idades mais jovens, caso a estrutura etária fosse a mesma da de 1970, as diferenças entre 1970 e 2000 seriam maiores. Com relação ao nível superior, a estrutura etária mais envelhecida contribuiu para aumentar a taxa em 2000.

O impacto das estruturas etárias diferentes de homens e mulheres, por educação, em 2000, mostrou que, caso aquelas nos graus médio e superior tivessem a mesma distribuição por idade que os homens, as taxas nesses graus seriam mais elevadas.

Heavens's door: immigration policy and the american economy. New Jersey: Princeton, University Press, 1999

CARVALHO, J. A. M. O saldo dos fluxos migratórios internacionais do Brasil na década de 80 - uma tentativa de estimação. Revista Brasileira de Estudos de População, v. 13, n. 1, 1996.

CASTILLA, F. M. Uma análise regional dos diferenciais sócio-econômicos da mortalidade na infância no Brasil 1960-1980. ENCONTRO DE ESTUDOS POPULACIONAIS, 10, Caxambu, 1996. Anais... Belo Horizonte: ABEP, 1996, v.4, p.2235-225.

CHISWICK, B.B. Is the new immigration less skilled than the old? Journal of Labour Economics, Chicago Illinois, v.4, n. 2, p.168192, 1986. 
DESPLANQUES, G. La mortalité des adultes suivant le milieu social 1955-1971. Collections de I'INSEE, Paris, n. 195, série D, n.44, 1976.

L'inegalité devant la mort. Économie et Statistique, Paris, v.162, p. 29-50, 1984.

ELO, I. T. ; PRESTON, S.H. Educational differentials in mortality in the United States, 1979-1985. Social Science and Medicine, London, v.42, n. 1, p. 47-57, 1996.

FELDMAN, J. J. et alii. National trends in educational differentials in mortality. American Journal of Epidemiology, Baltimore, Maryland, v. 129, n. 5, p.919-933, 1989.

FERNANDES, D. M. Diferenciais de mortalidade segundo instrução: regiões metropolitanas. Brasil, 1970. ENCONTRO DE ESTUDOS POPULACIONAIS, 4, Águas de São Pedro, 1984. Anais... ABEP, 1984, v.2, p.643-660.

GOUJON, A.; LUTZ, W. Future human capital: population projections by level of education demographic dimensions in forecasting: adding education to age and sex. In: LUTZ, W.C.S.; SCHERBOV, S. (Eds.). The end of world population growth in the $21^{\text {st }}$ century. London, IIASA, Earthscan, 2004, p.121-157

HAKKERT, R. Mecanismos subjacentes à relação entre a mortalidade infanto-juvenil e a educação dos pais. Revista Brasileira de Estudos de População, v.3, n.2, 1986.

KUNST, A. E.; MACKENBACH, J.P. The size of mortality differences associated with education level in nine industrialized countries. American Journal of Public Health, Washington D.C., v. 84, n. 6, p.932937, 1994.

LUTZ, W.; GOUJON, A.; DOBLHAMMER -REITER, G. Demographic dimensions in forecasting: adding education to age and sex. In: LUTZ, W.; VAUPEL, J.W.; AHLBURG, D.A. (Eds.). Frontiers of population forecasting. A supplement to v. 24, 1998, Population and Development Review. New York: The Population Council, 1999, p. 42-58.
MINGAT, A.; TAN, J. P. The full social returns to education: estimates based on countries' economic growth perfomance, Washington, D. C. World Bank, 1996 (Human Capital Working Paper, 16131).

PAPPAS, G. et alii. The increasing disparity in mortality between socioeconomic groups in the United States, 1960 and 1986. The New England Journal of Medicine, Waltham, Massachusetts, v. 329, n. 2, p. 103109, 1993.

PSACHARAPOULOS, G.; PATRINOS, H. Returns to investment in education: a further update. Washington D.C., World Bank, 2002 (World Bank Policy Research Working Paper, 2881).

RIGOTTI, J. I. R. Variáveis de educação dos censos demográficos brasileiros de 1960 a 200. In: RIOS-NETO, E.L.G.; RIANI, J.L.R. (Orgs.). Introdução à demografia da educação. Campinas: ABEP, 2004.

RIOS-NETO, E. L.G. Managing migration: the brasilian case. Belo Horizonte, Departamento de Demografia/Cedeplar/Face/ UFMG, fev. 2005 (Texto para discussão, 249).

SAWYER, D. O.; SOARES, E.S. Mortalidade na infância em diferentes no Brasil: variação nos efeitos de variáveis sócio-econômicas. ENCONTRO NACIONAL DE ESTUDOS POPULACIONAIS, 3, Vitória, 1982. Anais... Vitória: ABEP, 1982, v.1, p.567-570.

SANTOS, T. S.; MOURA, F. A. Os determinantes da mortalidade infantil no Nordeste: aplicação de modelos hierárquicos. ENCONTRO NACIONAL DE ESTUDOS POPULACIONAIS, 11, Caxambu, 1998. Anais... Belo Horizonte: ABEP, 1998, v.1.

SASTRY, N. Community characteristic, individual and household attributes, and child survival in Brazil. Demography, v. 33, n. 2, p. 211-229, May 1996.

. Trends in socioeconomic inequalities in mortality in developing countries: the case of child survival in São Paulo, Brazil. Demography, v. 41, n. 3, p. 443-465, August 2004. 
SHKOLNIKOV, V.M. et alii. Educational level and adult mortality in Russia: an analysis of routine data:1979 to 1994 . Social Science

and Medicine, London, v. .47, n. 3, p.357-369.

\section{Abstract \\ Evolution of education in Brazil: an analysis of educational rates between 1970 and 2000 according to highest grade concluded}

This article discusses the differences in rates of highest grade reached in school in Brazil by persons age 15 years and older between 1970 and 2000, according to age and gender group. For the higher age groups the expansion in formal education seems to have resulted in an increase in the number of persons with at least one grade of elementary education concluded, whereas for the younger brackets, the growth in the proportion of those with at least one year of senior high school [grades 9-11] and higher education concluded was more significant. Analysis by cohort showed a greater increase, during the period, among the younger cohorts and the women, in the proportion of persons in high school, and college or university. The older age brackets in $\mathbf{2 0 0 0}$ had little effect on the statistical growth of education in the country, and actually reduced the difference between the rates seen in 1970 and in 2000 for the levels of: no formal education, elementary education, and high school. But for the number of persons in higher education, this factor increased the difference. The distribution by educational level of legal international immigrants, as shown in the censuses of 1991 and 2000, contributes to an increase in the rates of higher levels of education.

Key words: Education attained. Immigration and education. Aging and education.

Recebido para publicação em 06/10/2005.

Aceito para publicação em 17/03/2006. 